\title{
Cost-effectiveness of patency capsule test prior to wireless capsule endoscopy
}

\author{
Authors: Keeley Fairbrass, ${ }^{A}$ Deloar Hoshen, ${ }^{A}$ Helen Bailey, ${ }^{A}$ Jason Jennings ${ }^{A}$ and Venkat Subramanian ${ }^{A}$
}

\section{Introduction}

Capsule endoscopy is a non-invasive technique intended for studying the small bowel and/or colon. It uses a small wireless camera to take pictures of the digestive tract. Although it is a safe procedure, it is possible for a capsule to become lodged in the digestive tract. A patency capsule is a pre-test that is now widely used prior to wireless capsule endoscopy (WCE) to reduce the incidence of capsule retention. ${ }^{1}$ The objective of this study is to evaluate the cost-effectiveness of the patency capsule test prior to WCE and to see whether selective use of it, by using an algorithm, is a cost-effective strategy.

\section{Materials and methods}

Patients who underwent the WCE and patency test between March 2016 and January 2018 were identified using the electronic endoscopy database. Electronic records and imaging were reviewed to assess indications, complications and outcomes. The Leeds Teaching Hospitals NHS Trust (LTHT) algorithm was used for selecting patients with high-risk features, suitable for patency capsule prior to WCE. High-risk features included known or suspected Crohn's disease, previous abdominal surgery, abdominal pain being the predominant symptom or those without prior abdominal imaging.

Differences between the group who had a patency test and the group who did not were analysed using Fisher's exact two-tailed test.

The 2016/2017 NHS tariff codes were used to calculate the direct costs associated with the procedure, radiological imaging, and treatment of associated complications. ${ }^{2} \mathrm{We}$ reviewed whether the application of an algorithm to select high-risk patients is beneficial both in terms of outcome and cost-effectiveness.

\section{Results and discussion}

A total of $214($ female $(\mathrm{f})=124 ;$ male $(\mathrm{m})=90)$ patients were referred for WCE in this period. Patients with a high risk of retention based on our algorithm had a patency capsule prior to WCE $\mathrm{n}=66(\mathrm{f}=33 ; \mathrm{m}=33)$, while $148(\mathrm{f}=91 ; \mathrm{m}=57)$ proceeded straight to WCE.

Authors: A Leeds Teaching Hospitals, Leeds, UK

\begin{tabular}{|c|c|c|c|c|c|c|c|}
\hline & & \multicolumn{2}{|c|}{ Scenario A } & \multicolumn{2}{|c|}{ Scenario B } & \multicolumn{2}{|c|}{ Scenario C } \\
\hline & $\begin{array}{c}\text { Average } \\
\text { cost per } \\
\text { patient (£) }\end{array}$ & $\begin{array}{l}\text { Patients } \\
\text { - no. (\%) }\end{array}$ & Cost (E) & $\begin{array}{l}\text { Patients } \\
\text { - no. (\%) }\end{array}$ & Cost (£) & $\begin{array}{l}\text { Patients } \\
\text { - no. (\%) }\end{array}$ & Cost (£) \\
\hline Patency capsule & 116 & $66(31)$ & 7,656 & $214(100)$ & 24,824 & 0 & 0 \\
\hline $\begin{array}{l}\text { Interventions required } \\
\text { from FP of patency }\end{array}$ & 81.50 & $24(36)$ & 1,956 & $77(36)$ & 6275 & 0 & 0 \\
\hline $\begin{array}{l}\text { Interventions required } \\
\text { from TP of patency }\end{array}$ & 119 & $2(3)$ & 238 & $6(3)$ & 714 & 0 & 0 \\
\hline $\begin{array}{l}\text { Cost of WCE } \\
\text { (-TP patients) }\end{array}$ & 771 & 212 & 163,452 & 208 & 160,368 & 214 & 164,994 \\
\hline $\begin{array}{l}\text { Interventions required } \\
\text { from FP of WCE }\end{array}$ & 31 & $10(5)$ & 310 & $10(5)$ & 310 & $88(41)$ & 6617 \\
\hline $\begin{array}{l}\text { Interventions required } \\
\text { from TP of WCE (eg. } \\
\text { surgical complications, } \\
\text { imaging) }\end{array}$ & 2,710 & 0 & 0 & 0 & 0 & $6(3)$ & 16,260 \\
\hline Total & & & 173,612 & & 192,491 & & 187,871 \\
\hline
\end{tabular}

Scenario A = using The Leeds Teaching Hospitals NHS Trust algorithm to select patients for patency prior to wireless capsule endoscopy; Scenario B = all patients referred for wireless capsule endoscopy also have patency capsule; Scenario

$\mathrm{C}=$ all patients straight to wireless capsule endoscopy without patency capsule.

A significant proportion of patients given a patency capsule were being investigated for small bowel enteropathy or Crohn's disease $(\mathrm{p}<0.001)$, while those with iron deficiency anaemia or obscure gastrointestinal (GI) bleeding generally went straight to test $(\mathrm{p}<0.001)$.

We identified $24(\mathrm{f}=16 ; \mathrm{m}=8)$ false-positive results with patency capsules, with additional investigation costs of $\mathfrak{E} 1,956$. Two ( $\mathrm{f}=1$; $\mathrm{m}=1$ ) true positive results with patency capsules had radiological

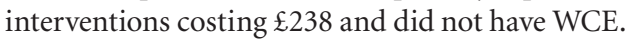

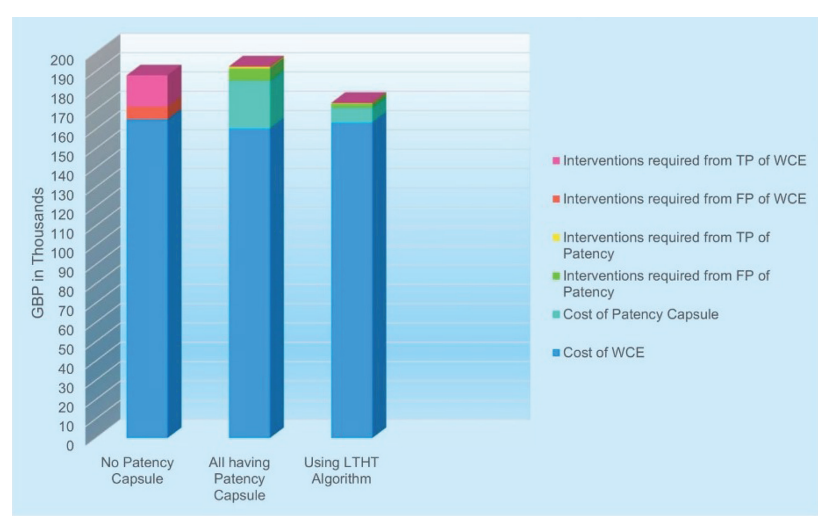

Fig 1. Costs in total for 214 patients in GBP (£). 
By applying our algorithm of selecting high-risk patients, we showed that the cost per patient for a WCE was $\mathfrak{E} 811$. This was cost-effective when compared with avoiding the use of patency capsules (£877 per patient) or using patency for all referrals prior to WCE ( $£ 899$ per patient; see Table 1 and Fig 1 ).

\section{Conclusion}

Using a selective approach to the use of patency capsules is cost-effective when compared with other strategies and saves between $\mathfrak{E} 66$ and $\mathfrak{E} 88$ per patient despite having a high rate $(36 \%)$ of false-positive tests.

\section{Conflicts of interest}

None declared.

\section{References}

1 Mustafa BF, Samaan M, Langmead L, Khasraw M. Small bowel video capsule endoscopy. Expert Rev Gastroenterol Hepatol 2013;7:323-9.

2 Department of Health and Social Care. NHS costing manual. GOV. UK, 2012. www.gov.uk/government/publications/nhs-costingmanual [Accessed 6 February 2020]. 